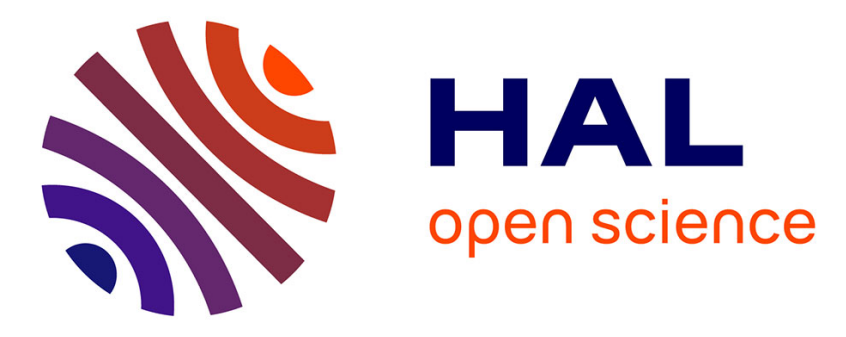

\title{
Influence of a pulsed laser regime on surface finish induced by thedirect metal deposition process on a Ti64 alloy
}

\author{
Myriam Gharbi, Patrice Peyre, Cyril Gorny, Muriel Carin, Simon Morville, \\ Philippe Le Masson, Denis Carron, Rémy Fabbro
}

\section{To cite this version:}

Myriam Gharbi, Patrice Peyre, Cyril Gorny, Muriel Carin, Simon Morville, et al.. Influence of a pulsed laser regime on surface finish induced by thedirect metal deposition process on a Ti64 alloy. Journal of Materials Processing Technology, 2014, 214 (2), pp.485-495. 10.1016/j.jmatprotec.2013.10.004 . hal-00980579

\section{HAL Id: hal-00980579 \\ https://hal.science/hal-00980579}

Submitted on 16 May 2014

HAL is a multi-disciplinary open access archive for the deposit and dissemination of scientific research documents, whether they are published or not. The documents may come from teaching and research institutions in France or abroad, or from public or private research centers.
L'archive ouverte pluridisciplinaire $\mathbf{H A L}$, est destinée au dépôt et à la diffusion de documents scientifiques de niveau recherche, publiés ou non, émanant des établissements d'enseignement et de recherche français ou étrangers, des laboratoires publics ou privés. 


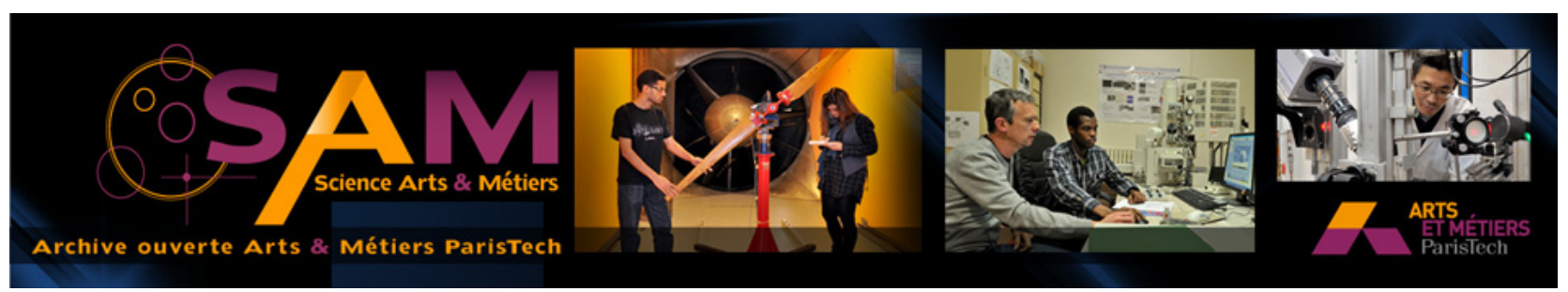

\section{Science Arts \& Métiers (SAM)}

is an open access repository that collects the work of Arts et Métiers ParisTech researchers and makes it freely available over the web where possible.

This is an author-deposited version published in: http://sam.ensam.eu

Handle ID: .http://hdl.handle.net/10985/7981

\section{To cite this version :}

Myriam GHARBI, Patrice PEYRE, Cyril GORNY, Simon MORVILLE, Philippe LE MASSON, Denis CARRON, Rémy FABBRO - Influence of a pulsed laser regime on surface finish induced by thedirect metal deposition process on a Ti64 alloy - Journal of Materials Processing Technology Vol. 214, n², p.485-495 - 2014 


\title{
Influence of a pulsed laser regime on surface finish induced by the direct metal deposition process on a Ti64 alloy
}

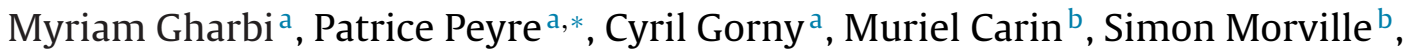 \\ Philippe Le Masson ${ }^{\mathrm{b}}$, Denis Carron ${ }^{\mathrm{b}}$, Rémy Fabbro ${ }^{\mathrm{a}}$ \\ a PIMM, UMR 8006 CNRS-Arts et métiers ParisTech, 75013 Paris, France \\ ${ }^{\mathrm{b}}$ LIMATB, Université de Bretagne-Sud, 56321 Lorient, France
}

\author{
Keywords: \\ Laser \\ Manufacturing \\ Deposition \\ Surface \\ Titanium
}

\begin{abstract}
A B S T R A C T
The direct metal deposition (DMD) laser technique is a free-form metal deposition process, which allows generating a prototype or small series of near net-shape structures. Despite numerous advantages, one of the most critical issues of the technique is that produced pieces have a deleterious surface finish which requires post machining steps. Following recent investigations where the use of laser pulses instead of a continuous regime was successful to obtain smoother DMD structures, this paper relates investigations on the influence of a pulsed laser regime on the surface finish induced by DMD on a widely used titanium alloy (Ti64). Findings confirm that using high mean powers improves surface finish but also indicate a specific effect of the laser operating mode: using a quasi-continuous pulsed mode instead of fully-cw laser heating is an efficient way for surface finish improvement. For similar average powers, the use of a pulsed mode with large duty cycles is clearly shown to provide smoothening effects. The formation of larger and stable melt pools having less pronounced lateral curvatures, and the reduction of thermal gradients and Marangoni flow in the external side of the fusion zone were assumed to be the main reasons for surface finish improvement. Additional results indicate that combining the benefits from a pulsed regime and a uniform laser irradiation does not provide further reduction of surface roughness.
\end{abstract}

\section{Introduction}

The direct metal deposition (DMD) or laser assisted direct fabrication technique is an attractive manufacturing technique that has been investigated since more than a decade, and allows obtaining sound and near net shape metallic parts from a three dimensional CAD model as indicated by Kobryn and Semiatin (2001), or more recently by Pinkerton (2010). In the DMD process, a high power focused laser beam (usually Nd:YAG, fiber or diode laser) is used as a heat source to selectively generate a molten pool on a substrate, where a coaxial powder feeding increases the material volume and contributes to the formation of a solid layer. The substrate is then scanned on $(x, y, z)$ directions below the (laser + powder nozzle) system and the layer-by-layer manufacturing of complex three dimensional metal parts is finally obtained.

Recently, other layer additive techniques like shape metal deposition, combining a wire feeding and a laser or a TIG welding torch have also been shown to manufacture sound and resistant Ti64

\footnotetext{
* Corresponding author. Tel.: +33 171936544.

E-mail address: patrice.peyre@ensam.eu (P. Peyre).
}

samples (Baufeld et al., 2011), with higher deposition rates than powder-based DMD, and a $100 \%$ efficiency. Compared with such techniques, the benefits of DMD are expected to come first from the multi-directionality of the powder feeding allowing the formation of more complex shapes, and second to the possibility to manufacture graded materials and to obtain better surface finish.

Many factors influence the DMD process efficiency, stability, or final metallurgical and mechanical properties, because of modifications of the global thermal cycle $T=f(t)$ experienced by each point of the fabricated structure. A large number of parameters are involved in the DMD process. The most frequently investigated are: laser power $P_{0}(\mathrm{~W})$, scan speed $V_{0}(\mathrm{~m} / \mathrm{min})$, laser diameter $d_{0}(\mathrm{~mm})$, and average powder flow rate $D_{\mathrm{m}}^{0}(\mathrm{~g} / \mathrm{min})$. Other experimental parameters (defocusing distance, gas shielding nature and gas flow rate, time delay between passes, spatial distributions of laser and powder etc.) also can have significant impact on the process. All these parameters, which are highly interactive in nature, influence the thermal history of the part, and contribute to the melt pool shapes, and the resulting layer growth (Peyre et al., 2008; Kumar and Roy, 2009). The manufactured parts are then defined by layer height " $\Delta h$ " and width " $e$ ", which can vary during the process, especially on complex shapes. 
However, limitations of the DMD process still remain such as:

(1) the need of a robust and reliable process control to maintain stationary local thermal conditions, and a stable and constant layer growth;

(2) the occurrence of a deleterious surface finish usually microscopic roughness $R_{\mathrm{a}}>15 \mu \mathrm{m}$ as shown by Maisonneuve et al. (2007) on Ti64 or Pinkerton and Li (2003) on AISI 316L, that requires intensive post-machining steps. Such surface finish restraints the applications of DMD to the drafts of final parts, contrary to selective laser melting (SLM) that allows obtaining better surface finishes, mostly because of the use of smaller powder grains and the formation of thinner additive layers.

The optimization and understanding of surface finish has never really been addressed in itself in previous work except in Gharbi et al. (2013). A common thought is that optimum surface finishes are mostly expected when using thin and stable deposited layers, when limiting melt pool disturbance, but without more precisions concerning process parameters, and melt pool shapes and dynamics. Moreover, as reminded by Pinkerton (2010), one can assume that melt pool stability depends on various internal forces (Marangoni flow, gravitational forces) or external forces (gas pressure, recoil forces near vaporization point, dynamic forces applied by the projected powder grains) applied on the molten metal.

Among the factors susceptible to smoothen surfaces, Zhu et al. (2012) have shown that positioning powder focus below the melt pool, and laser focus above was an efficient method, mostly due to a melt pool enlargement. Optimized process control, and limitations of melt pool fluctuations were also shown by Alimardani et al. (2012) to be possible contributors to surface finish improvements.

Pulsed laser regimes have already been used to manufacture parts using the DMD technique. Pinkerton and Li (2003) have pointed out a beneficial yet-limited effect of using pulsed laser irradiations (10-40 ms durations) on the surface roughness obtained on a 316L stainless steel. In another publication by Xue et al. (2011), near $2 \mu \mathrm{m}$ mean roughness $R_{\mathrm{a}}$ were obtained by DMD with the use of a pulsed mode on a Ni-based alloy, even if no precise indications on process parameters are given.

In a recent publication (Gharbi et al., 2013), the authors have shown that the generation of deep melt pools (of maximum height $=H$ ) combined with thin deposited layers $\Delta h$ was a keyfactor for ensuring good surface finish on Ti64 alloy, by favoring a reduction of lateral menisci, and a nearly total suppression of agglomerated particles. The resulting centrifugal Marangoni flow $(d \sigma / d T(\mathrm{~N} / \mathrm{m} \mathrm{K})<0)$ was assumed to act as a shaping contribution to the melt pool and to modify the resulting surface finish during layer additive processes. A simple analytical model was also proposed to calculate the meniscus mean amplitude $W_{\mathrm{p}}$ versus melt pool dimensions (height $H$, width $e$ ) and additive layer thickness $\Delta h$. For similar melt pool geometry (assumed to be elliptic), it was shown that smaller menisci (i.e. better surface finish) could be achieved with high $H / \Delta h$ ratio, and large melt pool width values. Another important result from Gharbi et al. (2013), was the beneficial influence of a top-hat laser distribution which was shown to act as a shaping effect on melt pool stabilized shape.

However, in additive layer manufacturing processes, questions still remained concerning the dependence between temperature distributions in the fusion zone, melt pool shapes, and final surface finish. Additionally, the precise influence of thermo-physical materials' properties was not addressed as we only considered Ti64 for our investigations.

The present paper is a logical continuity of this latter one, considering more specifically the simultaneous influence of pulsed regimes and laser spatial distribution on the surface roughness of Ti64 titanium alloy.

\section{Experimental conditions}

\subsection{Direct metal deposition conditions}

DMD tests (Fig. 1) have been carried out in pulsed regime using a HL 10002 continuous wave (cw) disk Yb:YAG laser operating at $1.03 \mu \mathrm{m}$, with 320-800 W peak laser powers, 2-10 ms pulse durations, and $40-100 \mathrm{~Hz}$ pulse frequency (Table 1 ).

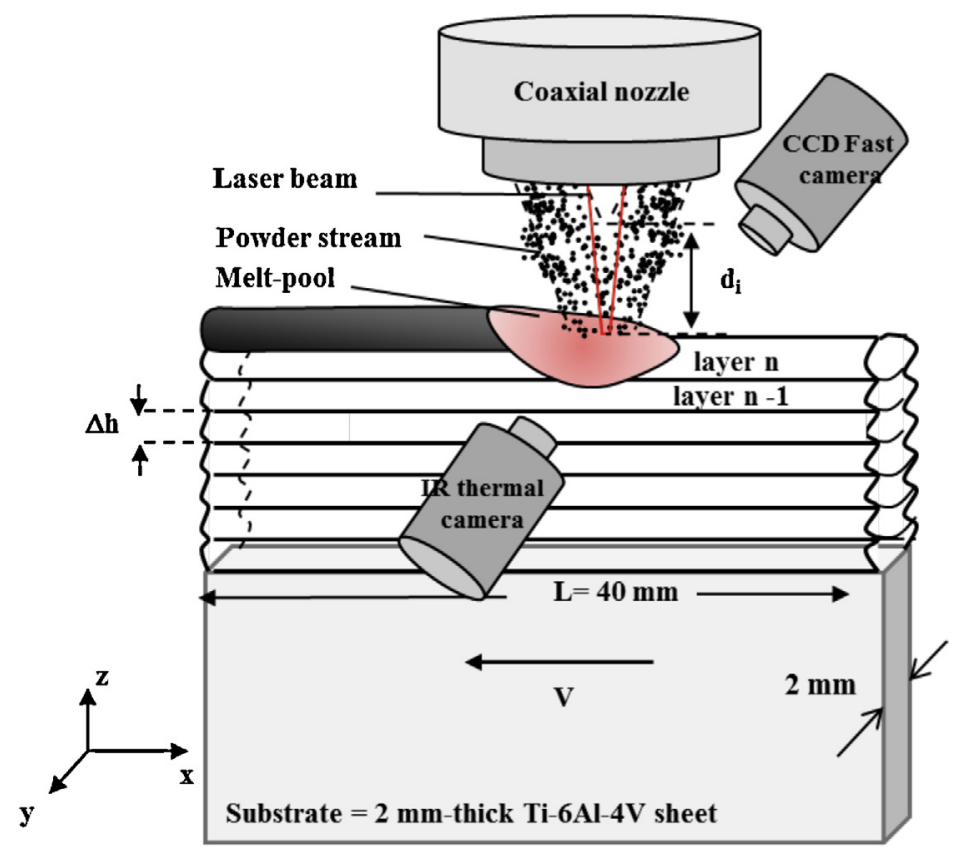

Fig. 1. Experimental DMD set-up and associated diagnostics (laser-powder-melt pool interaction zone), $\Delta h=$ layer height, $e=$ wall thickness. 
Table 1

Experimental DMD conditions (with $d_{\text {laser }}=2 r_{\text {laser }}$ ). With such conditions, deposition rates are between $0.05 \mathrm{~kg} / \mathrm{h}$ and $0.1 \mathrm{~kg} / \mathrm{h}$.

\begin{tabular}{|c|c|c|c|c|c|c|}
\hline Regime & Spatial distribution $+d_{\text {laser }}(\mathrm{mm})$ & Laser peak power $P_{\text {peak }}(\mathrm{W})$ & Scan speed $V(\mathrm{~m} / \mathrm{min})$ & Pulse durations (ms) & Frequency $f(\mathrm{~Hz})$ & Gas shielding \\
\hline Pulsed & Gaussian $1.2 \mathrm{~mm}$ & $500,600,800$ & 0.4 & $2-10 \mathrm{~ms}$ & $40,60,100$ & Argon \\
\hline Pulsed & Top-hat 1.7 mm & $500,600,800$ & 0.4 & $2-10 \mathrm{~ms}$ & $40,60,100$ & Argon \\
\hline Continuous & Gaussian $1.2 \mathrm{~mm}$ & $320,400,500$ & 0.4 & - & - & Argon \\
\hline
\end{tabular}

Two laser beam spatial distributions were used:

(1) A defocused near Gaussian laser spot $\left(\phi\left(\mathrm{W} \mathrm{m}^{-2}\right)=\right.$ $\left.5 P_{0} /\left(\pi r_{\text {laser }}^{2}\right) \exp \left(-5 x^{2} / r_{\text {laser }}^{2}\right)\right)$ provided by a $0.4 \mathrm{~mm}$ optical fiber delivery, and respectively $200 \mathrm{~mm}$ collimation and focusing lens in the laser head. The laser beam was used with a $+5 \mathrm{~mm}$ defocusing condition, resulting in a $1.2 \mathrm{~mm}$ diameter beam on the substrate (Fig. 2b).

(2) A top-hat laser spot $\left(\phi\left(\mathrm{W} \mathrm{m}^{-2}\right)=P_{0} /\left(\pi r_{\text {laser }}^{2}\right)\right)$ with $1.7 \mathrm{~mm}$ diameter obtained with a $600 \mu \mathrm{m}$ optical fiber, a $100 \mathrm{~mm}$ collimating lens and a $280 \mathrm{~mm}$ focusing lens.

Argon was used as a driving and shielding gas, in order to ensure powder transportation, and to limit oxidation phenomena. All the tests were carried out with a local Ar shielding (through the nozzle, and around), resulting in approximately $300 \mathrm{ppm} \mathrm{O}_{2}$ in the interaction zone, as confirmed by local $\mathrm{O}_{2}$ measurements. Even if the $\mathrm{O}_{2}$ content in $\mathrm{Ti}$ alloys has a well-known detrimental effect on mechanical properties, the influence of oxidation on surface finish was recently shown to be negligible in the [20-500 ppm] range (Gharbi et al., 2013).

For the powder distribution, a coaxial powder delivery nozzle system was used, with the powder flow rate directly proportional to the rotational speed of a delivery hopper. With this system, the Titanium powder (45-75 $\mu \mathrm{m}$, TLS Technik) is delivered coaxially with the laser beam, resulting in a $R_{\mathrm{p}} \approx 1.7 \mathrm{~mm}$ powder stream radius near the focus point (Fig. 2a), and with average mass feed rates $D_{\mathrm{m}}$ in-between $1 \mathrm{~g} / \mathrm{min}$ and $3 \mathrm{~g} / \mathrm{min}$. The mass feed profile was experimentally determined (Gharbi et al., 2013), and was shown to be near-Gaussian $\left(D\left(\mathrm{~g} / \mathrm{s} / \mathrm{m}^{2}\right)=5 D_{\mathrm{m}} /\left(\pi \cdot r_{\mathrm{p}}^{2}\right) \cdot \exp \left(-5 x^{2} / r_{\mathrm{p}}^{2}\right)\right)$. The factor 5 included in the analytical formulation was shown to provide the best fitting with the local mass feed rate distribution measured experimentally.

The relative positioning of laser beam versus powder stream is presented in Fig. $1\left(d_{\mathrm{i}}=\right.$ interaction distance between powder stream and laser beam $\approx 1 \mathrm{~mm}$ ). All the DMD tests have been carried out with $40 \mathrm{~mm}$-length/6-15 mm-height walls, starting from $2 \mathrm{~mm}$-thick titanium sheets (Fig. 1), and with scan speeds in the $0.1-0.6 \mathrm{~m} / \mathrm{min}$ range. A $10 \mathrm{~s}$ time pause was used between each layer to limit heat accumulation on wall edges, and two opposite directions were considered for the deposition (forward and backward). Experimental conditions are summarized in Table 1.

\subsection{Fast camera analysis}

A simultaneous coaxial and lateral recording of melt pool sizes and dynamics was carried out, using two synchronized fast cameras with C-Mos sensors (Photron), at frequency rates up to $4000 \mathrm{~Hz}$, using KG3 filters to cut the laser wavelength $(1.053 \mu \mathrm{m})$, and halogen lights to improve the contrast of recorded images. This allowed us to analyze melt pool dimensions (length $L$, height $H$, area $S$ ) and flow (fluid velocity $v_{\mathrm{f}}$ ) in order to try to correlate them with surface finish data.

\subsection{Temperature measurements in fusion zones}

The determination of temperature fields in melt pools was carried out using a new spectrometer-based method developed by Muller et al. (2012). This allowed us to determinate in two steps: (1) the emissivity and local temperature at the surface of the melt pool on a $500 \mu \mathrm{m}$ diameter spot using a spectrometer, (2) the 2D temperature distribution by correlating gray levels from a C-Mos fast camera (obtained with luminance temperatures). The emissivity was calibrated using the melting point of pure elements such as Niobium and Tungsten. A $\varepsilon=0.37 \pm 0.02$ emissivity was found in the $0.5-0.7 \mu \mathrm{m}$ spectral window (interferential filter) used for melt pool analysis. This allowed us to quantify the thermal field by correlating gray levels of pixels to local temperatures. More data concerning the method are available in Muller et al. (2012). The overall objective of thermal analysis was to assess temperature maximum values and gradients, with the objective of predicting thermo-convective effects.
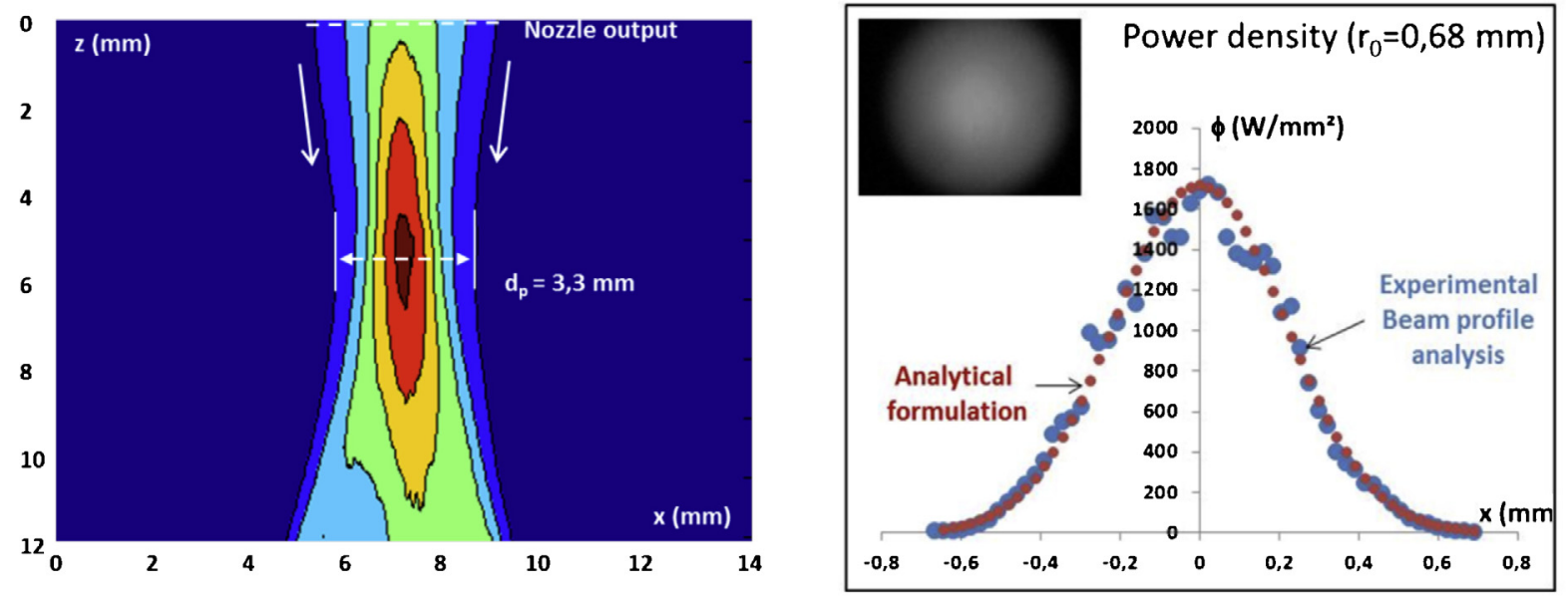

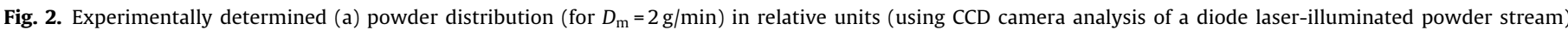

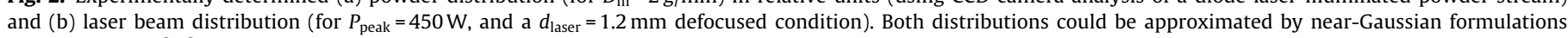
$\left(f(x)=A \cdot \exp \left(-5 x^{2} / r^{2}\right)\right)$. 


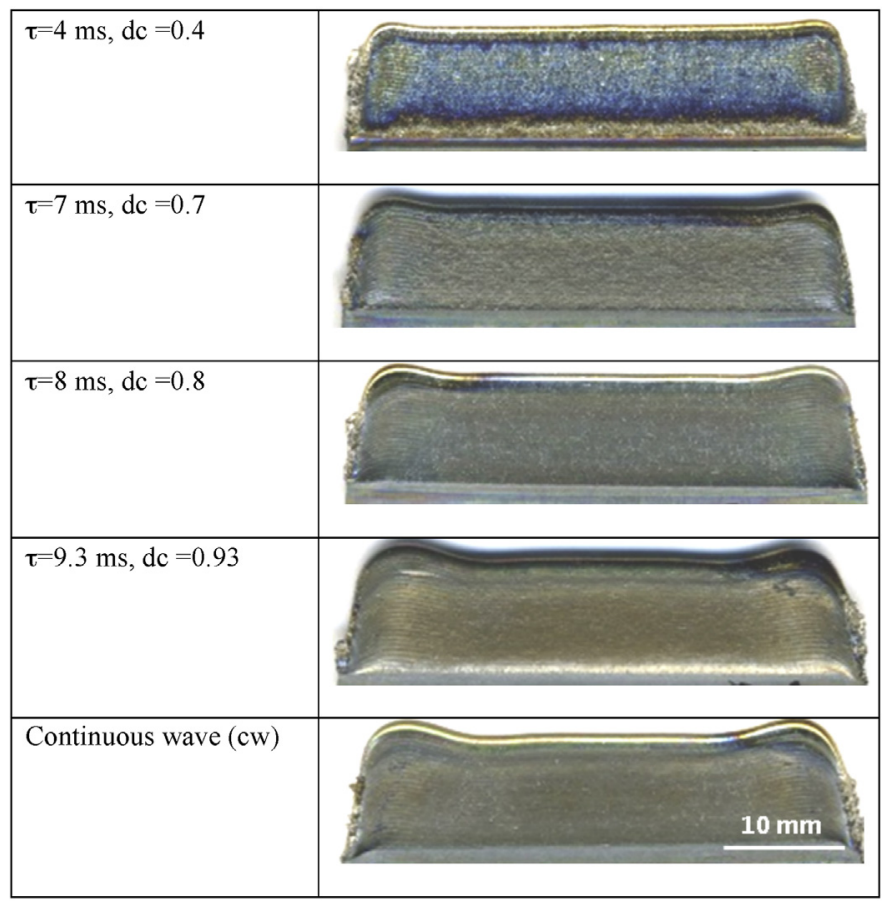

Fig. 3. Scanned images of DMD walls ( $40 \mathrm{~mm}$ length) obtained at $P=600 \mathrm{~W}$, $V=0.4 \mathrm{~m} / \mathrm{min}, D_{\mathrm{m}}=1 \mathrm{~g} / \mathrm{min}, f=100 \mathrm{~Hz}$ in pulsed regime (dc = duty cycle).

\subsection{Surface analysis}

DMD surfaces exhibit a periodic structure composed of an accumulation of lateral menisci directly due to the equilibrium shapes of the melt pool. Manufactured walls were analyzed using: (1) low and medium magnification optical microscopy to visualize the global surface aspect and the grain microstructure (after Kroll's etching), (2) scanning electron microscopy (SEM-FEG Hitachi 4802 II) to provide a local description of DMD surfaces, (3) 2D and 3D profilometry (Veeco Dektak 150) to quantify surface topography. An example of scanned pictures of DMD walls is shown in Fig. 3.

\section{Experimental characterization of the DMD melt pools}

\subsection{Melt pool dynamics and melt pool dimensions versus process parameters}

Different regimes of melt pool behavior could be achieved, depending on the duty cycles dc (=laser pulse duration $\tau$ divided by the laser period $T=1 / f$ ), corresponding to the time ratio of laser "on" to total time. Examples of more or less pronounced variations of the melt pool size during the DMD process are shown in Figs. 4 and 5. The " $S$ " surface was measured considering the projected image of melt-pools view on CCD sensors, followed by a contour determination using Image J software. In Figs. 4 and $5 b$, for a dc $=0.6$, the lateral melt pool surface varies of $25 \%$ during two laser periods whereas in Fig. $5 a$, for a smaller dc value (0.3) a $50 \%$ fluctuation of the melt pool is shown (Fig. 5a). Using such procedures, we could evidence different kind of behavior for the melt pool: (1) below a given dc value $\left(\mathrm{dc}_{\mathrm{th} 1} \approx 0.1-0.25\right.$ dependent on the peak power $\left.P_{\text {peak }}\right)$, a complete solidification is achieved between two pulses, (2) above a high dc value ( $\mathrm{dc}_{\mathrm{th} 2} \approx 0.85-0.95$ ), the melt pool does not fluctuate and can be considered as geometrically stable, and (3) in-between those two dc thresholds, fluctuations of the melt pool gradually increase (Fig. 5a and b).

If we now consider melt pool dynamics (Marangoni convection flow), by analyzing particle velocities at the surface of the melt pool, a centrifugal flow is systematically observed, with average fluid velocities close to $0.4 \mathrm{~m} / \mathrm{s}$, consistent with results obtained in $\mathrm{cw}$ regime. For low dc value (below $\mathrm{dc}_{\mathrm{th} 1}$ ), the hydrodynamic flow

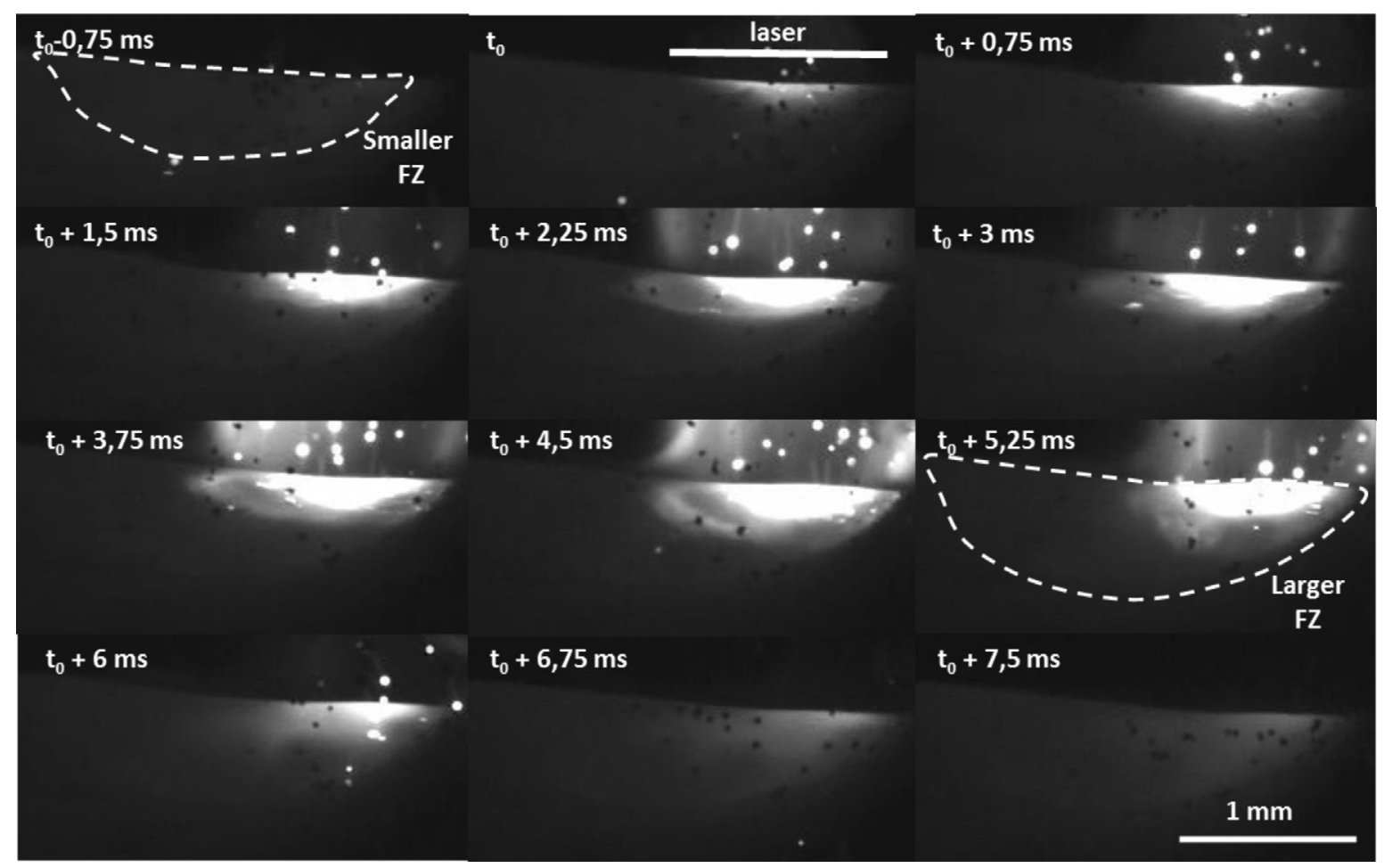

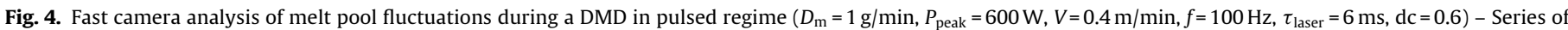

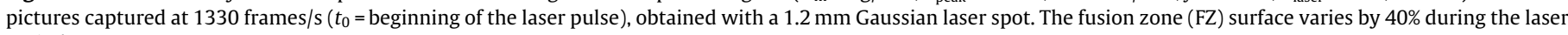
period. 

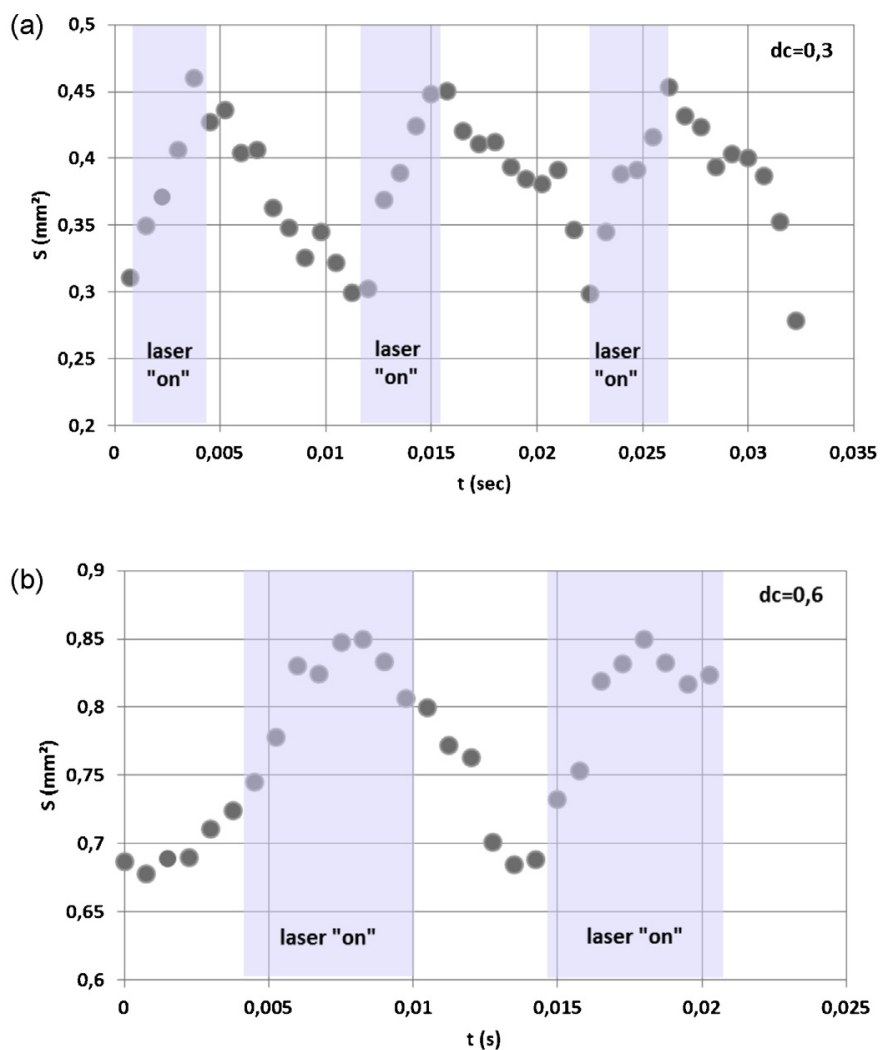

Fig. 5. Fast camera analysis of melt pool fluctuations (projected surface $S$ ) with time for 2 different duty cycles $\left(P_{\text {peak }}=600 \mathrm{~W}-100 \mathrm{~Hz}(10 \mathrm{~ms}\right.$ period)): (a) $\tau=3 \mathrm{~ms} \rightarrow \mathrm{dc}=0.3$ and (b) $\tau=6 \mathrm{~ms}$, dc $=0.6$. A $50 \%$ fluctuation of the melt pool is obtained for $\mathrm{dc}=0.3$, and a $25 \%$ fluctuation of $\mathrm{S}$ is obtained for $\mathrm{dc}=0.6$.

seems to be reduced, and the fusion zone (FZ) experiences mostly a quasi-hydrostatic behavior.

\subsection{Analysis of melt pool temperatures}

The determination of temperature fields in titanium melt pool is important because it allows us quantifying temperature gradients, and resulting surface tensions gradients and fluid velocities, due to thermo-capillary convection. Another important aspect is the determination of maximum temperatures susceptible to favor vaporization of alloying elements such as aluminum $\left(T_{\mathrm{V}}=2500^{\circ} \mathrm{C}\right)$. Among the main issue for thermal measurements in small melt pools: the determination of the emissivity $\varepsilon$ of the melt titanium alloy which requires a pre-calibration, and the need of a good spatial resolution. A specific method was developed for this purpose using a pyrometer system coupled with a CCD fast camera analysis of the fusion zones.

The influence of duty cycles on temperature fields was more specifically investigated.

When comparing two duty cycles $(\mathrm{dc}=0.53$ and $\mathrm{dc}=0.9)$, the following observations can be done:

(1) Increasing the dc value and the resulting mean power logically tends to increase the maximum temperature in the FZ. This temperature is nearly $3080 \mathrm{~K}$ for $\mathrm{dc}=0.53$ and $3320 \mathrm{~K}$ for $\mathrm{dc}=0.9$.

(2) Thermal fluctuations $\Delta T$ in the melt-pool during one single laser period decrease with dc (Figs. 5 and 6).

(3) For instance, a 0.53 dc value generates a maximum temperature decay $\Delta T=(3080-2270)=810 \mathrm{~K}$ between $t=5.3 \mathrm{~ms}($ at the (a)

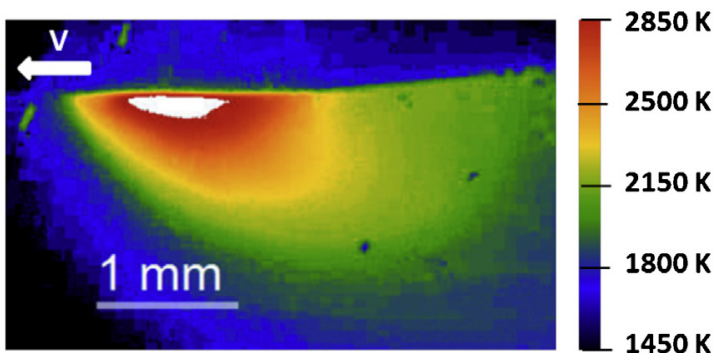

(b)
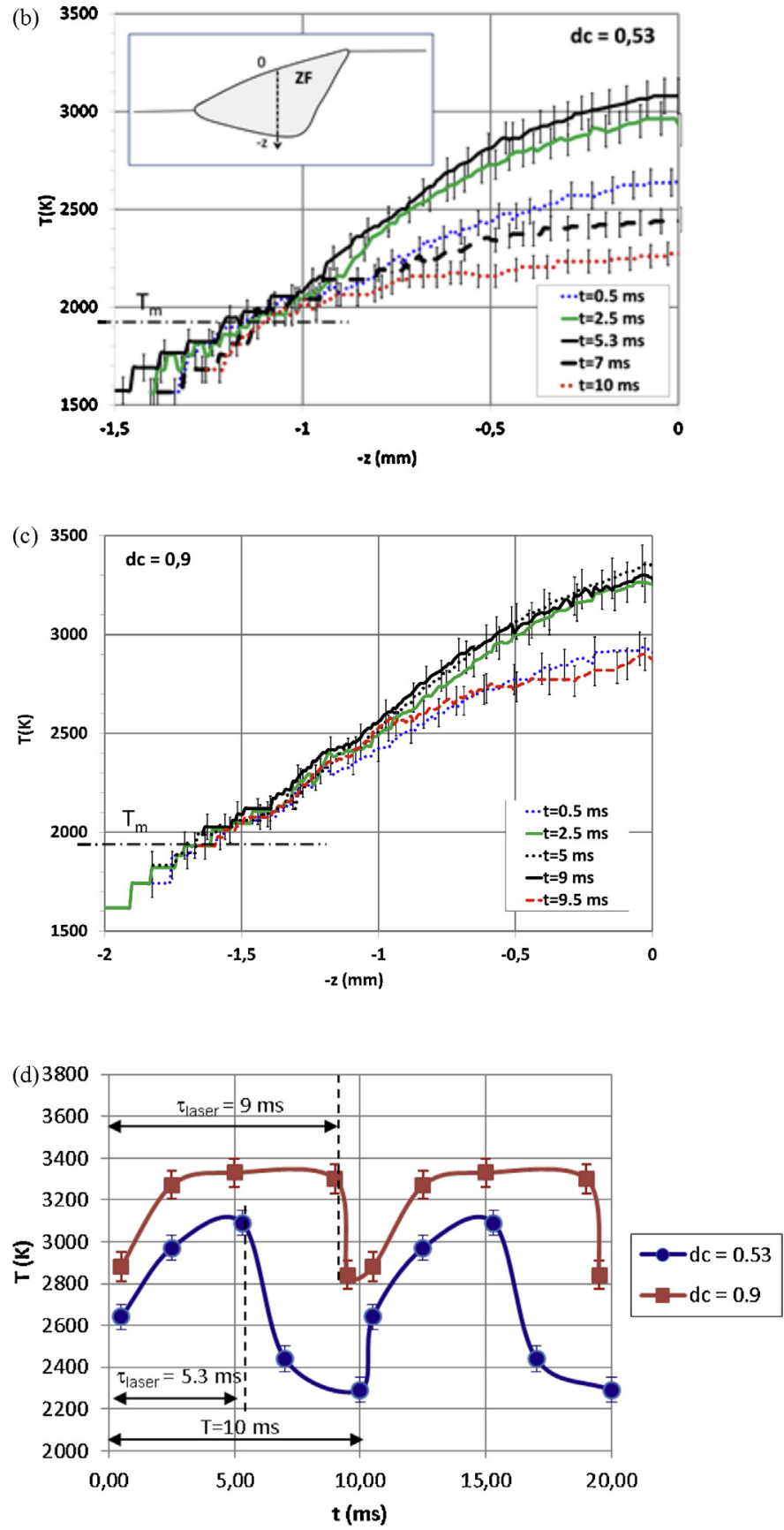

Fig. 6. Temperature distribution at the surface of the melt pool $(100 \mathrm{~Hz}$, $P_{\text {peak }}=600 \mathrm{~W}, V=0.4 \mathrm{~m} / \mathrm{min}$, Gaussian irradiation) using fast camera + pyrometer system - (a) example of side view thermal image of the melt pool captured during a time period, (b) $d c=0.53$, (c) dc $=0.9$, (d) variation of temperature with time. 
(a)

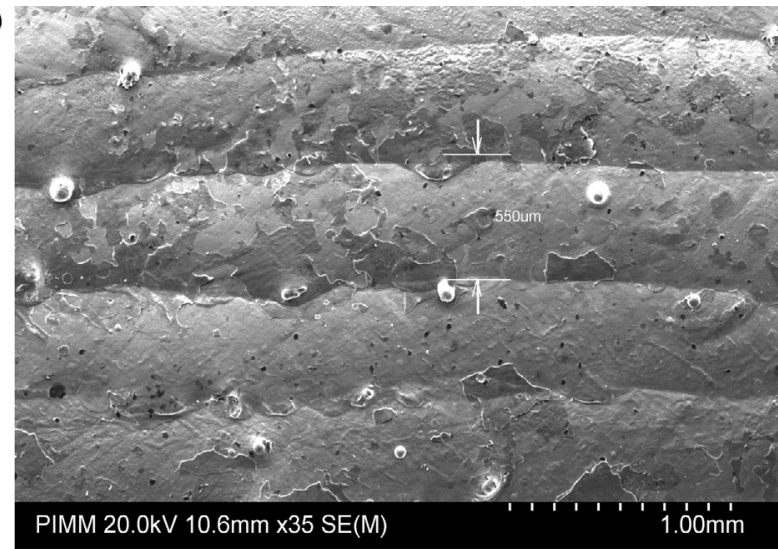

(b)

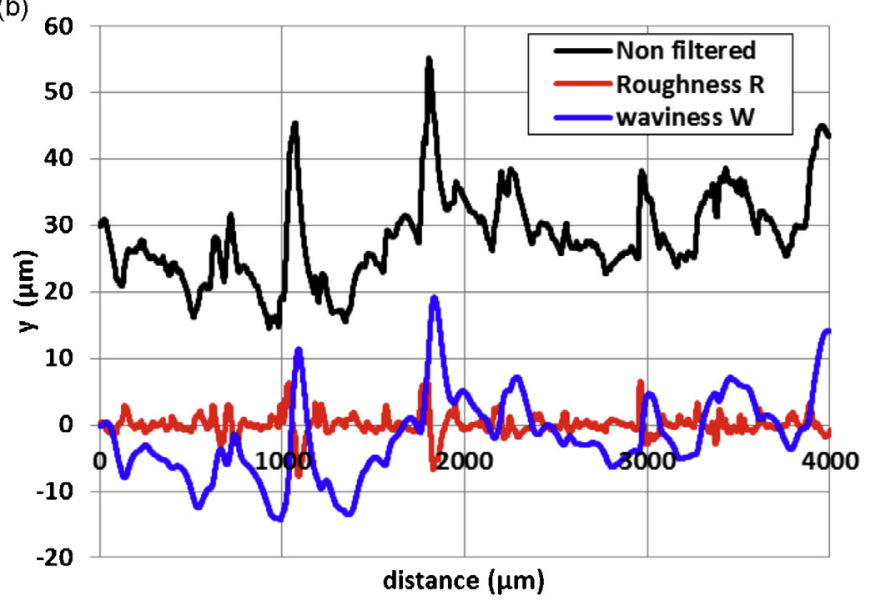

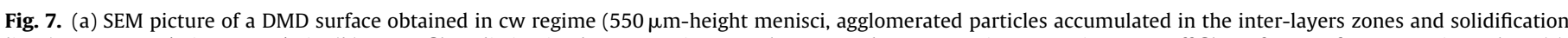

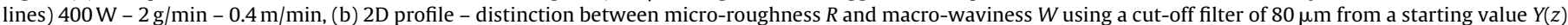

end of the laser pulse), and $t=10 \mathrm{~ms}$ (just before a new pulse), whereas a $0.9 \mathrm{dc}$ value limits $\Delta T$ value to $(3320-2850)=470 \mathrm{~K}$.

(4) The maximum temperature achieved for $\mathrm{dc}=0.9$ corresponds to the boiling point of Ti64 $(3320 \mathrm{~K})$, and its time-dependence seems to exhibit a plateau (Fig. 6). This result indicates that a vapor pressure could have been applied on the $\mathrm{FZ}$, resulting in possible shape modifications.

It was also clearly shown that the pulsed regime generates much higher maximum temperatures than the cw regime at similar mean powers. For instance, if we compare the maximum temperature evidenced in Fig. $6 \mathrm{c}$ (for $\mathrm{dc}=0.53$ and $P_{\text {peak }}=600 \mathrm{~W}, P_{\text {mean }}=318 \mathrm{~W}$ ) with the corresponding test in $\mathrm{cw}$ regime $(320 \mathrm{~W}, \mathrm{cW})$, the $\mathrm{cW}$ regime generates a $T_{\max }=2600 \mathrm{~K}$ versus $3080 \mathrm{~K}$ in pulsed regime.

\subsection{Evolution of surface finishes with process parameters for a Gaussian beam distribution}

\subsubsection{General approach}

With the use of SEM analysis (Fig. 7a), two kinds of surface roughness were distinguished, as already shown in Gharbi et al. (2013):

(1) a microscopic contribution coming from (a) particle agglomerations mostly located in inter-layers areas, (b) solidification lines, (c) possible oxide layers. This micro contribution is favored by small melt pools, and rather low temperature distributions around the melt pool;

(2) the formation of periodic menisci, directly correlated to the melt pool stability (Fig. 7a).

For differentiating macroscopic waviness contribution $\left(W_{\mathrm{a}}, W_{\mathrm{t}}\right)$ from microscopic roughness $\left(R_{\mathrm{a}}, R_{\mathrm{t}}\right)$ parameters, a cut-off filter (threshold $d_{\mathrm{th}}=80 \mu \mathrm{m}$ ) was used (Fig. 7b), just above the maximum diameter of particles $(75 \mu \mathrm{m})$ that usually provoke micro-roughening when agglomerating on the wall edges. The $R_{\mathrm{a}}$ and $W_{\mathrm{a}}$ values correspond to arithmetic average values (Eq. (1)) whereas $R_{\mathrm{p}}$ and $W_{\mathrm{p}}$ correspond to peak-to-average line values (Eq. (2)). $W_{\mathrm{p}}$ data can be directly compared to the meniscus height. All measurements were carried out on a $d_{\text {total }}=4 \mathrm{~mm}$ - length distance, using 3-4 tests for each DMD condition to provide statistically reliable data.

$R_{\mathrm{a}}, W_{\mathrm{a}}=\frac{1}{d} \cdot \int_{0}^{d_{\mathrm{th}}}|Y(z)| \cdot d z$
$R_{\mathrm{p}}, W_{\mathrm{p}}=\frac{1}{d} \cdot \int_{0}^{d_{\mathrm{th}}}\left|Y_{\mathrm{nf}}(z)\right| \cdot d z$

With $d=d_{\text {th }}$ for $R$ values and $d=d_{\text {total }}$ for $W$ values, $Y(z)=$ non filtered line profile with $Y(z)=0$ as average line value, and $Y_{\mathrm{nf}}(z)=$ non filtered line profile with $Y_{\mathrm{nf}}(z)=Y(z)+Y_{\text {max,peak }}$ (Raphet, 2008).

\subsubsection{Influence of a pulsed regime - case of a Gaussian laser irradiation}

Most of the results presented on Ti64 in a recent publication (Gharbi et al., 2013) were obtained for a $1.2 \mathrm{~mm}$ Gaussian laser irradiation. In turn, the specific influence of a pulsed regime, considering the same spatial distribution, was important. First of all, wall and melt pool dimensions (width " $e$ ", apparent height " $H$ ", height par layer " $\Delta h$ ") induced either in cw or in pulsed regime were compared at similar mean power $\left(P_{\text {mean }}=P_{\text {peak }} \times \mathrm{dc}\right)$, revealing a very low dimensional change (Fig. 8).

In a second step, the variation of surface parameters versus duty cycles (Figs. 9-11) was analyzed and provided us the following information:

(1) In pulsed regime, the increase in duty cycles limits the amount of agglomerated particles and globally improves surface finish (Fig. 9 for a Gaussian laser spot). This occurs whatever the laser frequency $(60 \mathrm{~Hz}$ or $100 \mathrm{~Hz}$, Fig. 10).

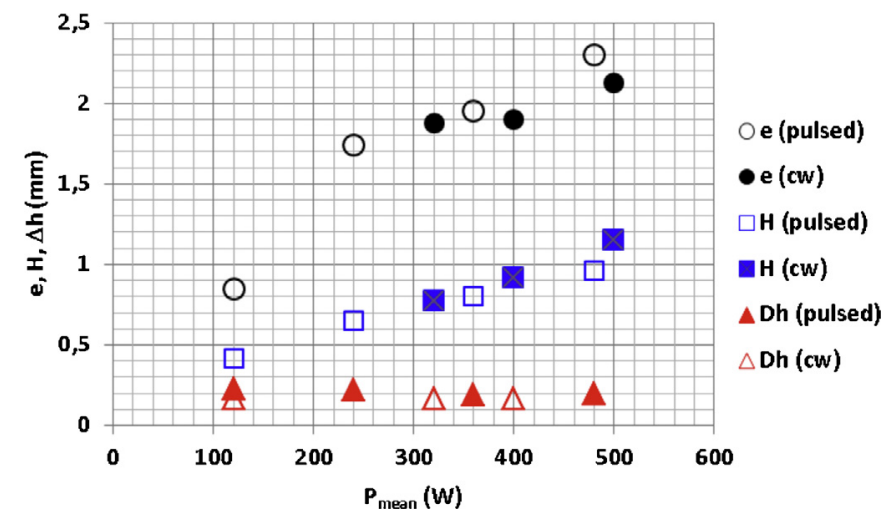

Fig. 8. Comparison of melt pool dimensions for walls manufactured either in continuous or pulsed regimes at similar mean power $\left(P_{\text {mean }}=P_{\text {peak }} \times \mathrm{dc}\right)$ : no clear difference is shown between the pulsed $\left(P_{\text {peak }}=600 \mathrm{~W}, 60 \mathrm{~Hz}\right)$ and cw regime $(e=$ wall and meltpool width, $H$ = apparent melt-pool height = maximum melt-pool height measurable by lateral camera analysis, $\Delta h=$ additive layer height). 
(a)

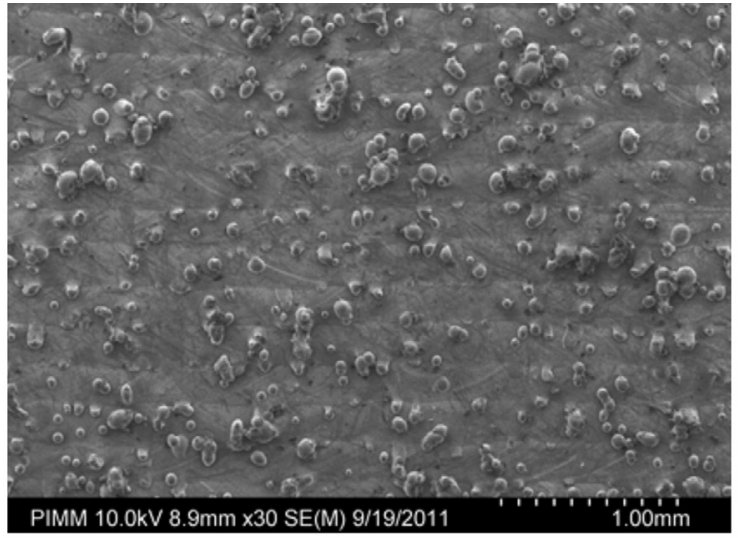

(c)

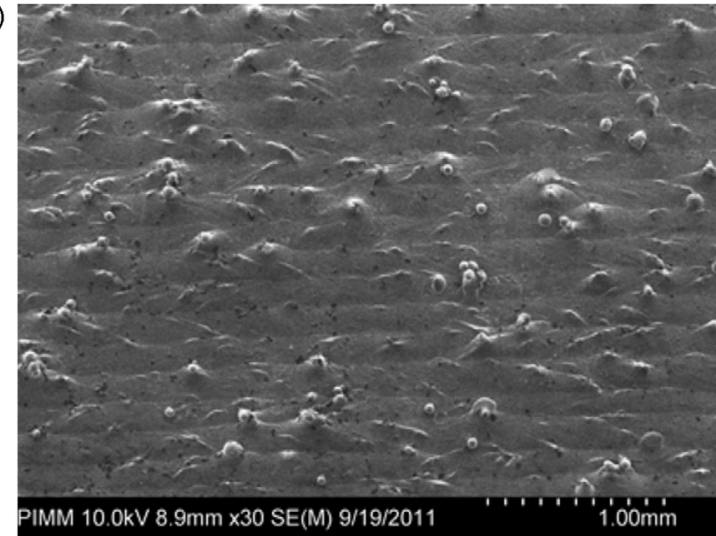

(b)

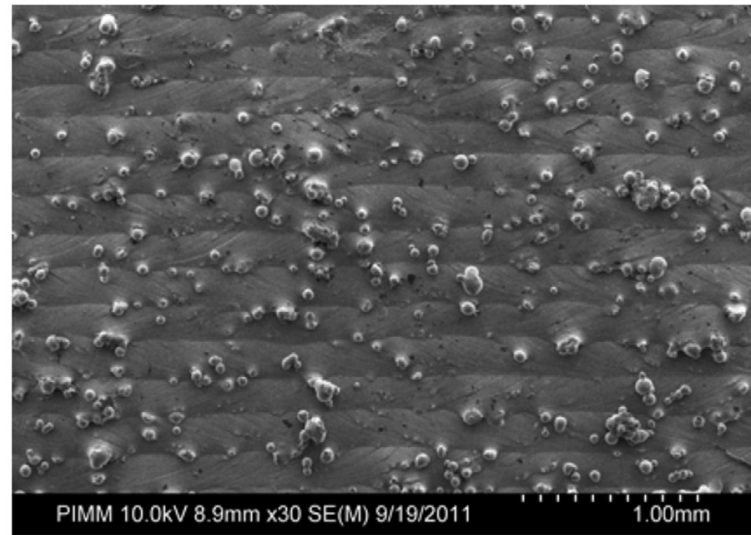

(d)

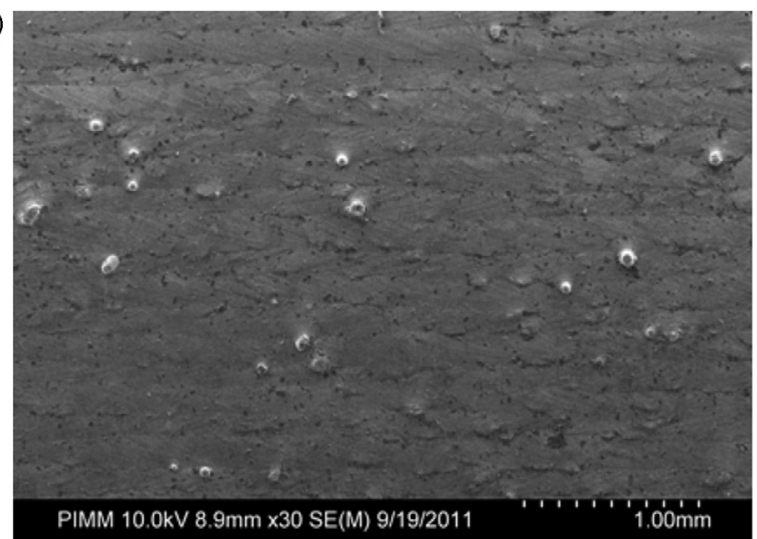

Fig. 9. SEM pictures of DMD surfaces obtained in pulsed regime $\left(P_{\text {peak }}=600 \mathrm{~W}-f=60 \mathrm{~Hz}-D_{\mathrm{m}}=1 \mathrm{~g} / \mathrm{min}\right)-$ Influence of the duty cycle $(\mathrm{a}) \mathrm{dc}=0.36$, (b) $\mathrm{dc}=0.48$, (c) dc $=0.6$, (d) $\mathrm{dc}=0.84$.

(a)

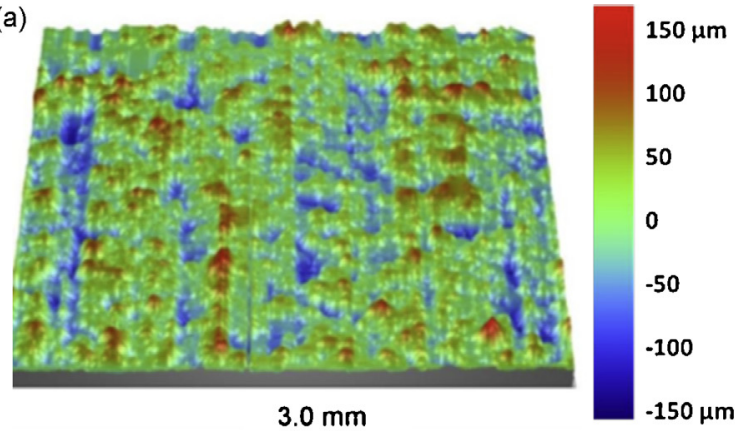

(c)

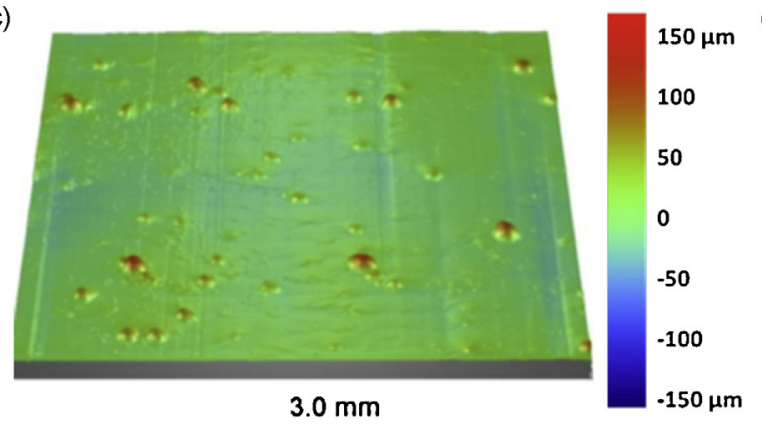

(b)

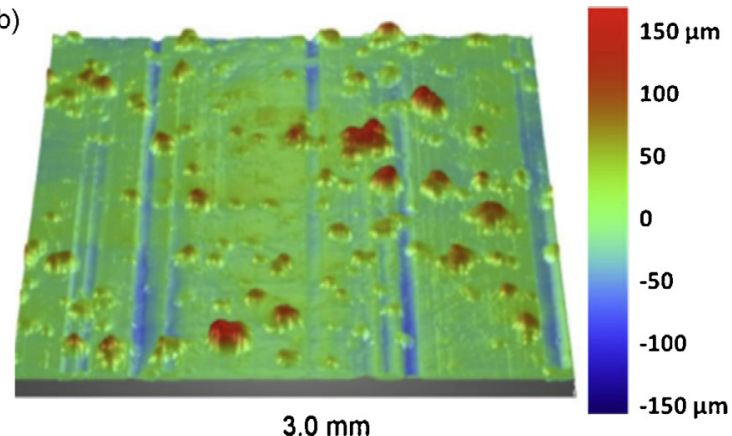

(d)

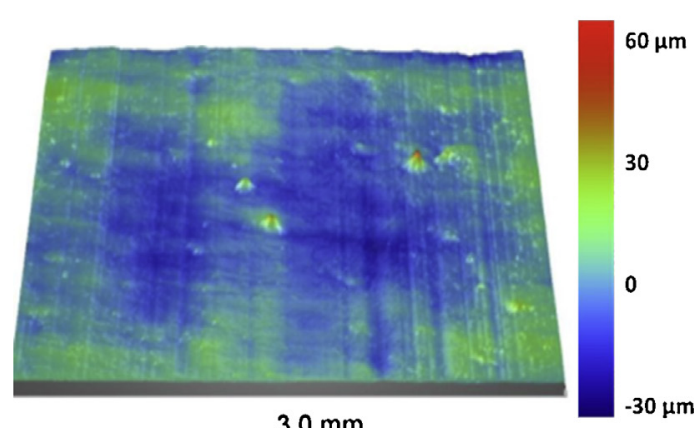

Fig. 10. 3D profiles of surface finish induced in pulsed regime $\left(P_{\text {peak }}=500 \mathrm{~W}-f=60 \mathrm{~Hz}, D_{\mathrm{m}}=1 \mathrm{~g} / \mathrm{min}\right)(\mathrm{a}) \mathrm{dc}=0.3$ (non-filtered average roughness $\left.=R_{\mathrm{anf}}=29 \mu \mathrm{m}\right)$, (b) dc $=0.5$ $\left(R_{\mathrm{a}, \mathrm{nf}}=17 \mu \mathrm{m}\right),(\mathrm{c}) \mathrm{dc}=0.7\left(R_{\mathrm{a}, \mathrm{nf}}=9 \mu \mathrm{m}\right),(\mathrm{b}) \mathrm{dc}=0.9\left(R_{\mathrm{a}, \mathrm{nf}}=5 \mu \mathrm{m}\right)$. 

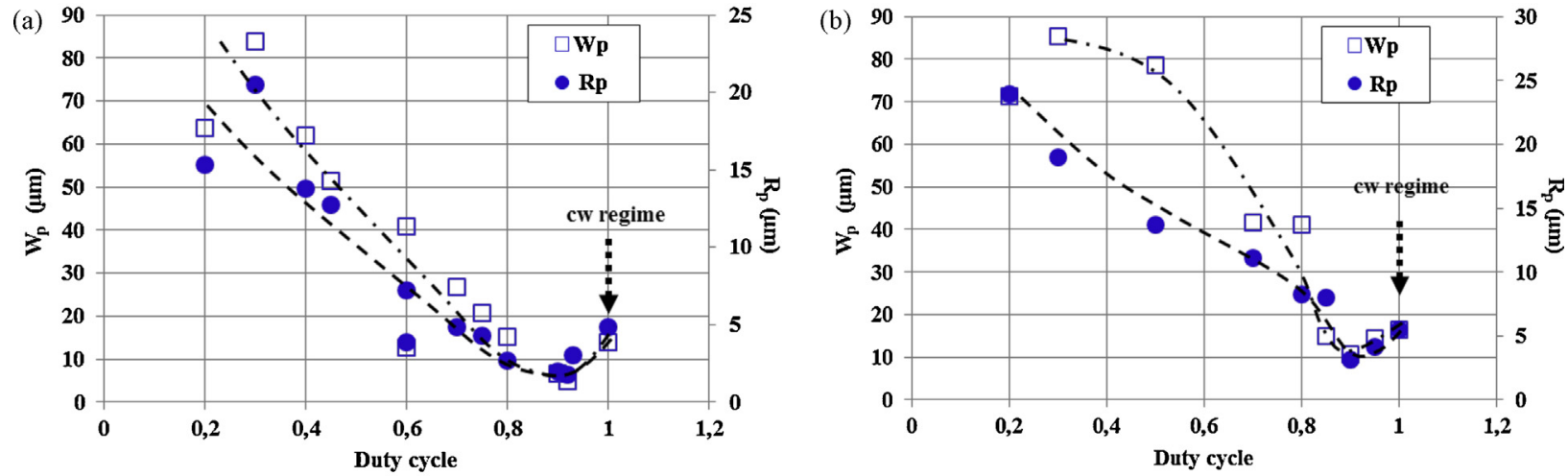

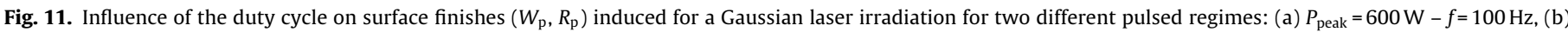
$P_{\text {peak }}=500 \mathrm{~W}-f=60 \mathrm{~Hz}$.

(2) The continuous decrease of both waviness and roughness parameters with dc value reveals a beneficial influence of the mean laser power $\left(P_{\text {mean }}=P_{\text {peak }} \times \mathrm{dc}\right)$ with increasing duty cycles. High $P_{\text {mean }}$ induce thicker melt pools that promote high $H / \Delta h$ and $e / \Delta h$ values (Gharbi et al., 2013) which tend: (1) to reduce particle agglomerations (the local mass feed rate that modifies particle concentration decreases with wider meltpool), (2) to reduce meniscus height (the melt-pool lateral curvature radius decreases with deeper and wider melt-pools).

(3) At a given frequency $f$, the best surface finish is obtained for a quasi-continuous pulsed regime $(\mathrm{dc} \approx 0.9)$. A significant benefit is obtained compared with the cw regime: a factor 2 increase of $R, W$ parameters is obtained between $\mathrm{dc}=0.9$ and $\mathrm{dc}=1(\mathrm{cw})$ (Fig. 11).

(4) At similar dc values, if we compare surfaces manufactured at $60 \mathrm{~Hz}-P_{\text {peak }}=500 \mathrm{~W}$ and $100 \mathrm{~Hz}-P_{\text {peak }}=600 \mathrm{~W}$, the best surface finish is clearly obtained for the higher peak power (Fig. 10). Additional tests, carried out at $60 \mathrm{~Hz}-600 \mathrm{~W}$, have confirmed that the laser frequency in itself was not a key-point.

(5) Non-filtered roughness values (cut-off $=0$ ), indicate optimum roughness values near $R_{\mathrm{a}}=2 \mu \mathrm{m}$ and $R_{\mathrm{p}}=5 \mu \mathrm{m}$. Such values are much lower than those from previously published data on Ti64 (Maisonneuve et al., 2007).

To emphasize the specific influence of a pulsed versus cw regime, surface parameters induced by the two regimes were compared, on a large range of mean powers (Fig. 12). Even at similar mean power $\left(P_{\text {mean }}=P_{\text {peak }} \times \mathrm{dc}\right)$, corresponding to a similar global heat input, the quasi-continuous pulsed regime induced better

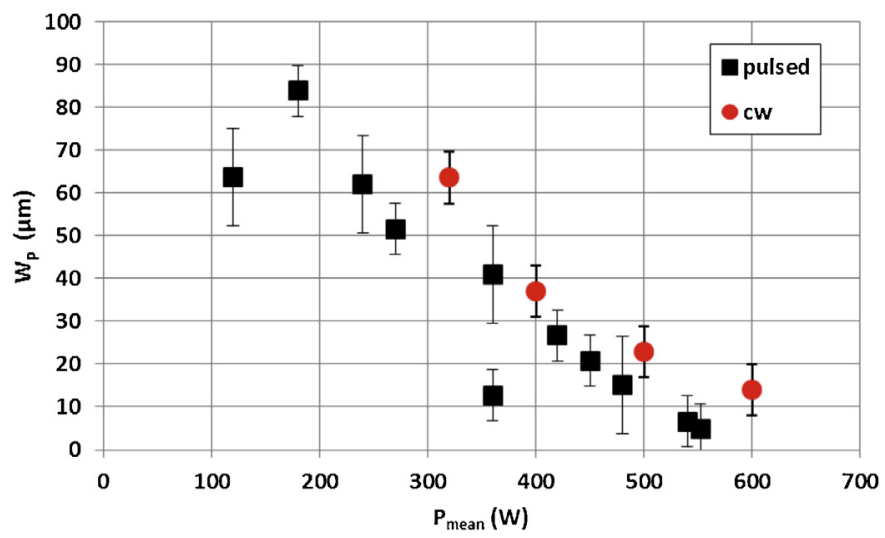

Fig. 12. Influence of interaction regime ( $\mathrm{cw}$ or pulsed) and mean power on surface finish (pulsed regime considered for $P_{\text {peak }}=600 \mathrm{~W}$ and various dc), Gaussian laser irradiation $1.2 \mathrm{~mm}$. surface finish that the continuous regime. Consequently, a real benefit from the pulsed regime at high duty cycle could be assumed, especially for high mean powers.

\subsection{Influence of the beam distribution on surface finish obtained in pulsed regime}

Previous results presented in Gharbi et al. (2013) have shown the benefit from using a uniform $1.7 \mathrm{~mm}$ "top-hat" laser distribution instead of a $1.2 \mathrm{~mm}$ Gaussian irradiation in $\mathrm{cw}$ regime. Following this, comparative tests were carried out in pulsed regime to address a possible additional effect of spatial distribution (1.7 mm top-hat instead of $1.2 \mathrm{~mm}$ Gaussian) on surface finish. Before addressing surface finish, one has to remind two aspects:

(1) the temperature distribution in the melt pools is more homogeneous for the top-hat distribution, than for the Gaussian irradiation, resulting in reduced thermal gradients and expected Marangoni flow;

(2) despite the reduction of thermal gradients, expected to inhibit centrifugal flow that enlarge melt pools, melt pool dimensions are nearly kept constant by the $1.7 \mathrm{~mm}$ top-hat irradiation, due to a better spatial distribution of heat input (higher power density values near the edges of the laser irradiation zone).

The analysis of waviness parameter $W_{p}$ (i.e. the height of the lateral menisci) was shown to indicate a moderate surface finish improvement with Gaussian irradiation at similar mean powers (Fig. 13). Moreover, with a $1.7 \mathrm{~mm}$ top-hat irradiation, the best

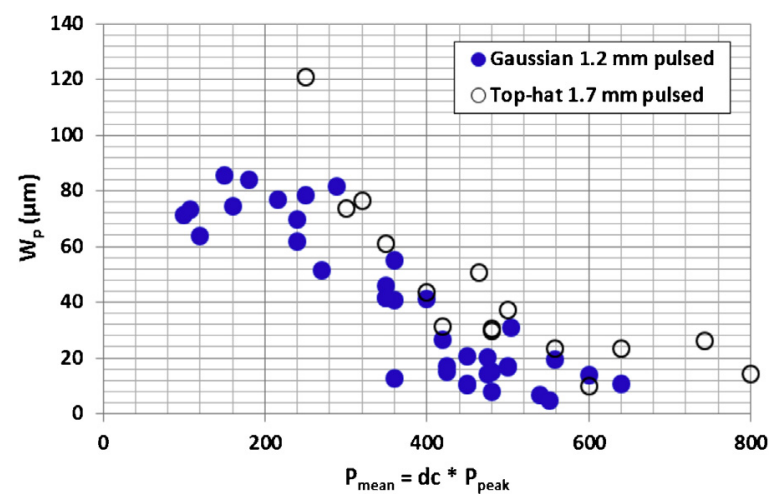

Fig. 13. Influence of the laser beam spatial distribution on the surface finish induced in pulsed regime for one peak power $P_{\text {peak }}=600 \mathrm{~W}$, two frequencies $(60 \mathrm{~Hz}$ and $100 \mathrm{~Hz}$ ), and various duty cycles dc. For similar duty cycles the Gaussian irradiation mostly generates better surface finish. 
(a)

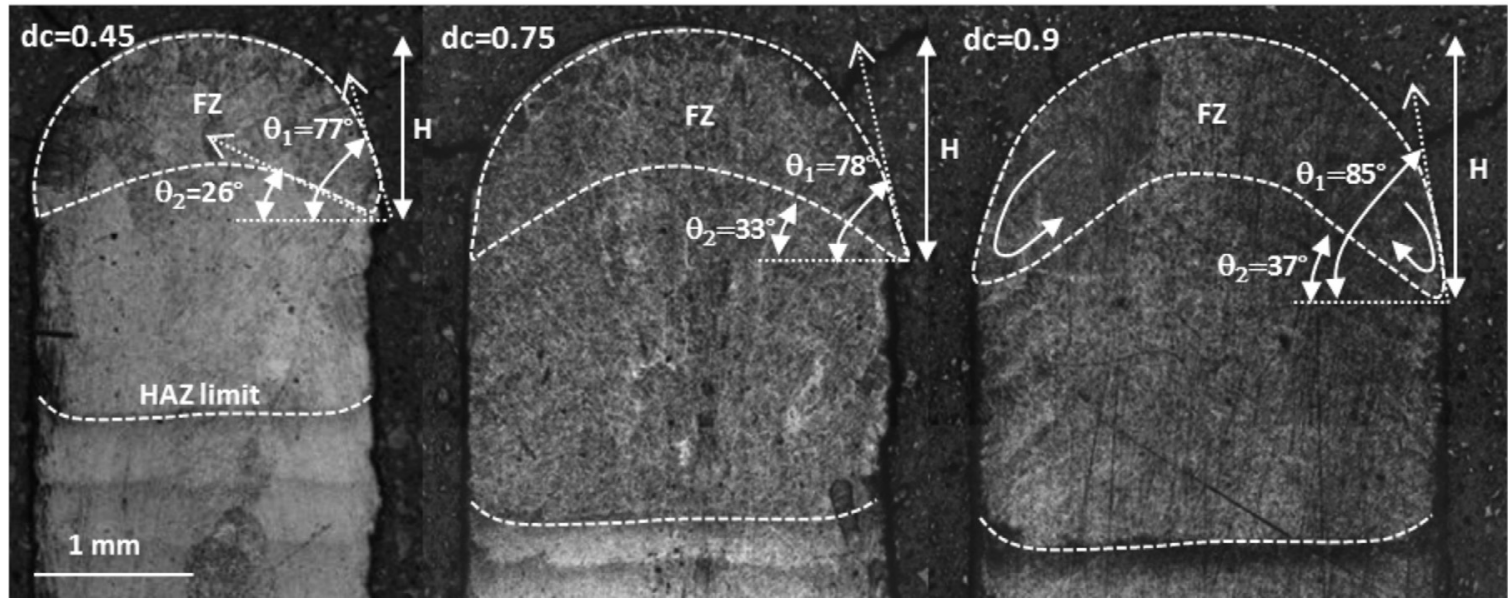

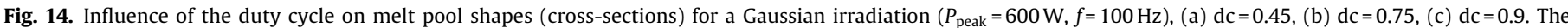

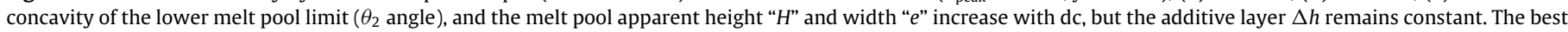
surface finish is obtained for the higher dc values and the higher $\theta$ values.

surface finish was obtained for a $\mathrm{dc}=1$, i.e. for a $\mathrm{cw}$ irradiation, whereas for the Gaussian distribution, minimum $\mathrm{W}$ values were evidenced for $\mathrm{dc} \approx 0.9$. Consequently, it seems that the real benefit from a quasi-continuous regime is mostly evidenced for a Gaussian laser irradiation, where thermal gradients in the fusion zone are higher than for the top-hat distribution. It was also assumed that, for mean powers above $600 \mathrm{~W}$ (top-hat $1.7 \mathrm{~mm}$ ), vapor pressure effects acting as a normal force on the melt-pool, could have increased meniscus height by expanding laterally the melt-pool, thus provoking an increase of $W_{\mathrm{p}}$ parameters.

\subsection{Discussion: influence of a pulsed regime on melt pool shapes and surface finish obtained with the DMD technique}

For a given spatial distribution of the laser beam (Gaussian), experimental results clearly evidence optimum surface finish with the use of a pulsed DMD regime, especially when using high duty cycles corresponding to quasi-continuous laser irradiations. The benefit of using a near continuous pulsed regime is assumed to be attributed to a combination of physical factors:

(1) The best surface finishes are obtained for high mean powers $P_{\text {mean }}$, corresponding to high $H / \Delta h$ factors, as previously demonstrated in Gharbi et al. (2013). The improvement is shown not only on meniscus height $(W)$ but also on microroughness data $(R)$. Globally, thicker and wider melt pools limit solid particle sticking by limiting the local mass feed rate coincident to the lateral edges of the walls, favor particles re-melting, and in turn tend to limit the amplitude of lateral menisci, and the density of agglomerated particles.

(2) Provoking a discontinuity in laser irradiation ( $\approx$ using a quasi-continuous pulsed regime) allows reducing temperature gradients, interrupting Marangoni lateral flows, and enhancing lateral menisci curvature. The resulting effect is a decrease of the mean velocity in the melt pool, which could not be fully demonstrated experimentally by CCD cameras, but which was confirmed by thermo-hydraulic numerical simulations (Morville et al., 2011), (Morville, 2012). This decrease is assumed to be the main reason why $\mathrm{W}$ factors are improved by pulsed regimes when carried out with similar mean powers than with a cw regime.

On metallurgical cross-sections of the samples (using Kroll's reagent etching), the use of higher duty cycles logically promotes melt pool enlargements, and more pronounced concavities (increased $\theta$ angles) due to more severe Marangoni flow $(\partial \sigma / \partial T<0$ on Ti64), together with deeper melt pool (Fig. 14). Large dc values also improve surface finish as shown in Fig. 11. This result is consistent with what has been previously demonstrated in cw regime (Gharbi et al., 2013).

However, when comparing melt pool shapes induced by nearly similar mean powers in cw or pulsed regime (for instance: a $500 \mathrm{~W}$ $\mathrm{cW}$ irradiation and a $\left(P_{\text {peak }}=600 \mathrm{~W}-\mathrm{dc}=0.9\right)$ pulsed configuration corresponding to a $P_{\text {mean }}=540 \mathrm{~W}$ mean power), a significant difference is shown on the fusion zone (FZ) height, and on the concavity angles $\theta_{1}$ and $\theta_{2}$ (Fig. 15). The interesting point is that not only the dimensions, but also the FZ shape is modified by the use of the pulsed regime. This seems to indicate a modification of the local fluid flow, which could not be evidenced with fast cameras, but which has a real effect on melt pool shapes and resulting surface finish.

The resulting conclusion is that not only the apparent (and maximum) melt pool $H$ height and the additive layer $\Delta h$, but also the local $\theta$ angles at the lateral side of melt pools are the dominant factors that influence the meniscus height, and in turn the $W$ roughness parameter: the higher the $\theta$ values, the lower the $W$ parameters (Fig. 16). In a previous publication (Gharbi et al., 2013), elliptic melt pool shapes were considered, including $H$ and $\Delta h$ in an analytical prediction of $W$ values, but without really addressing the local lateral shape of the FZ in terms of $\theta_{1}$ and $\theta_{2}$ angles. One of the most unexpected result is that $\theta_{1}$ and $\theta_{2}$ values are modified by DMD parameters, but do not systematically follow the larger thermal gradients and the higher Marangoni flow. For instance, the comparison between the pulsed mode and the cw mode shows that higher $\theta$ angles and better surface finish are obtained with the pulsed mode, which is shown to reduce $\partial T / \partial y$ gradients in the FZ. A first order estimation of the $\mathrm{W}$ value can be obtained using $\theta_{1}$ and $\theta_{2}$ angles (Eq. (3)). However, for the calculation, very local $\theta_{1}$ and $\theta_{2}$ angles were considered, near the edge of the FZ.

$W=\frac{\Delta h}{\tan \left(\theta_{1}\right)-\tan \left(\theta_{2}\right)}$

For nearly identical FZ dimensions, the influence of a pulsed regime on roughness values (=particles agglomerated) is not so obvious. Classically, wider walls tend to reduce local mass feed rates $D_{\mathrm{m}}^{*}\left(\mathrm{~g} / \mathrm{s} / \mathrm{m}^{2}\right)$ in front of the lateral wall edges (Fig. 16), and contribute to a roughness decrease. However, wall dimensions obtained in cw or pulsed regime are nearly identical for similar 
(a)

(b)

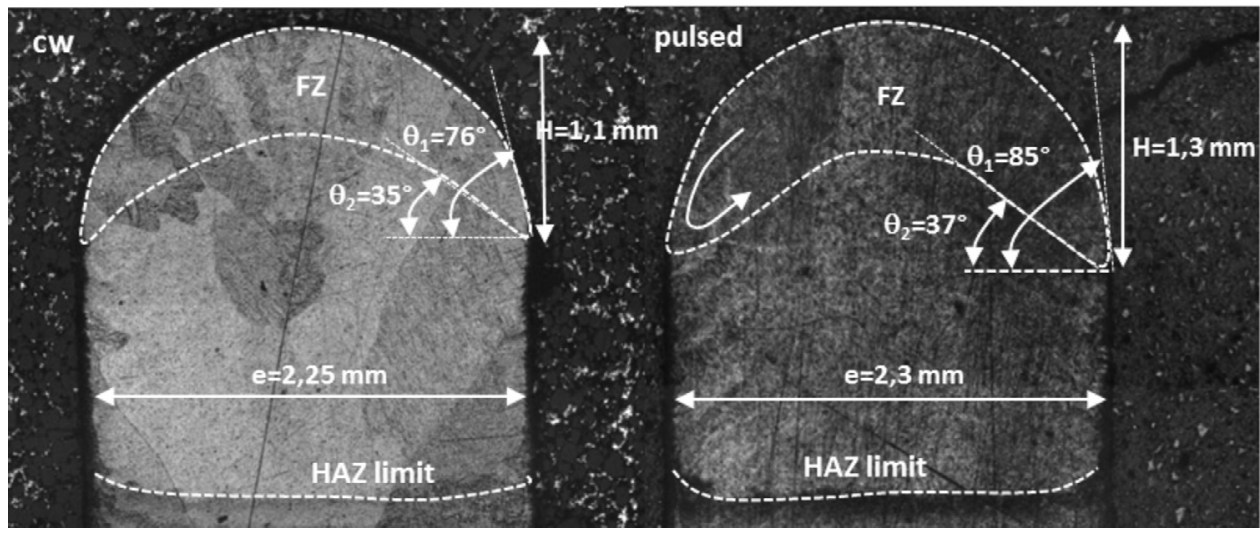

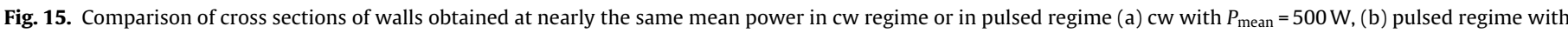
$P_{\text {peak }}=600 \mathrm{~W}$ and $\mathrm{dc}=0.9$ (corresponding to $P_{\text {mean }}=540 \mathrm{~W}$ ). Almost similar wall dimensions, but the pulsed regime induces more concave FZ (higher $\theta_{1}$ and $\theta_{2}$ angles).

mean powers (Fig. 8). Consequently, it was assumed that it was the lateral FZ shape modification (increase of $\theta_{1}$ and $\theta_{2}$ angles $\approx$ more vertical curvature of the FZ) which limited particle sticking, instead of the reduction of local mass feed rate $D_{\mathrm{m}}^{*}$.

If we now consider a uniform beam distribution (top-hat $1.7 \mathrm{~mm}$ ) already shown to be beneficial for surface improvements (Gharbi et al., 2013), combined with a pulsed regime, no further improvement was shown compared to the Gaussian $1.2 \mathrm{~mm}$ irradiation (Fig. 13). Consequently, starting from a cw Gaussian DMD process, two distinct options are possible for improving surface finish: either (1) the use of a quasi-continuous pulsed regime or (2) the use of a cw top-hat irradiation. The combination of these two factors (a pulsed top-hat DMD) did not provide additional improvement of surface finish.

With such optimized conditions, attractive surface finish could be obtained (Table 2), with $R_{\mathrm{a}}$ and $R_{\mathrm{p}}$ as measured (non-filtered) values of respectively $3-5 \mu \mathrm{m}$ and 7-18 $\mu \mathrm{m}$, and mass efficiency ratios $\varpi$ (of approximately $50-75 \%$ better with a top-hat $1.7 \mathrm{~mm}$ irradiation due to larger melt pools). Corresponding experimental parameters allow combining optimum surface finish with acceptable efficiency rates. However, the manufactured volume per hour remains low $\left(10 \mathrm{~cm}^{3} / \mathrm{h}\right.$ of Ti64), due to low mass feed rates $(1 \mathrm{~g} / \mathrm{min})$ which are a dominant factor for achieving smooth surfaces. Such roughness data indicate a decrease of the main (non-filtered) roughness parameters by a factor of more than 5 , compared with previously published data on Ti64 alloy. With this experimental procedure, post-machining steps are expected to be strongly reduced, and the DMD technique already allows providing similar or even-better surface finish than the SLM technique (Fig. 17).

In a final step, SEM-EDS investigations were carried out in order to check possible compositional changes on DMD samples, especially for those manufactured with high peak powers, where very high local temperatures were measured (Fig. 6). Those temperatures, locally superior to $3200 \mathrm{~K}$, are expected to promote intensive vaporization of $\mathrm{Al}$ (boiling temperature $T_{\mathrm{b}}=2782 \mathrm{~K}$ ) or Ti64 $\left(T_{\mathrm{b}}=3330 \mathrm{~K}\right)$. However, EDS analysis did not point out changes $\mathrm{Al}$ and $\mathrm{V}$ compositions, even for high $P_{\text {mean }} / V$ ratio. Moreover, no real hardness difference was shown between samples

Larger, deeper and more curvated melt-pools

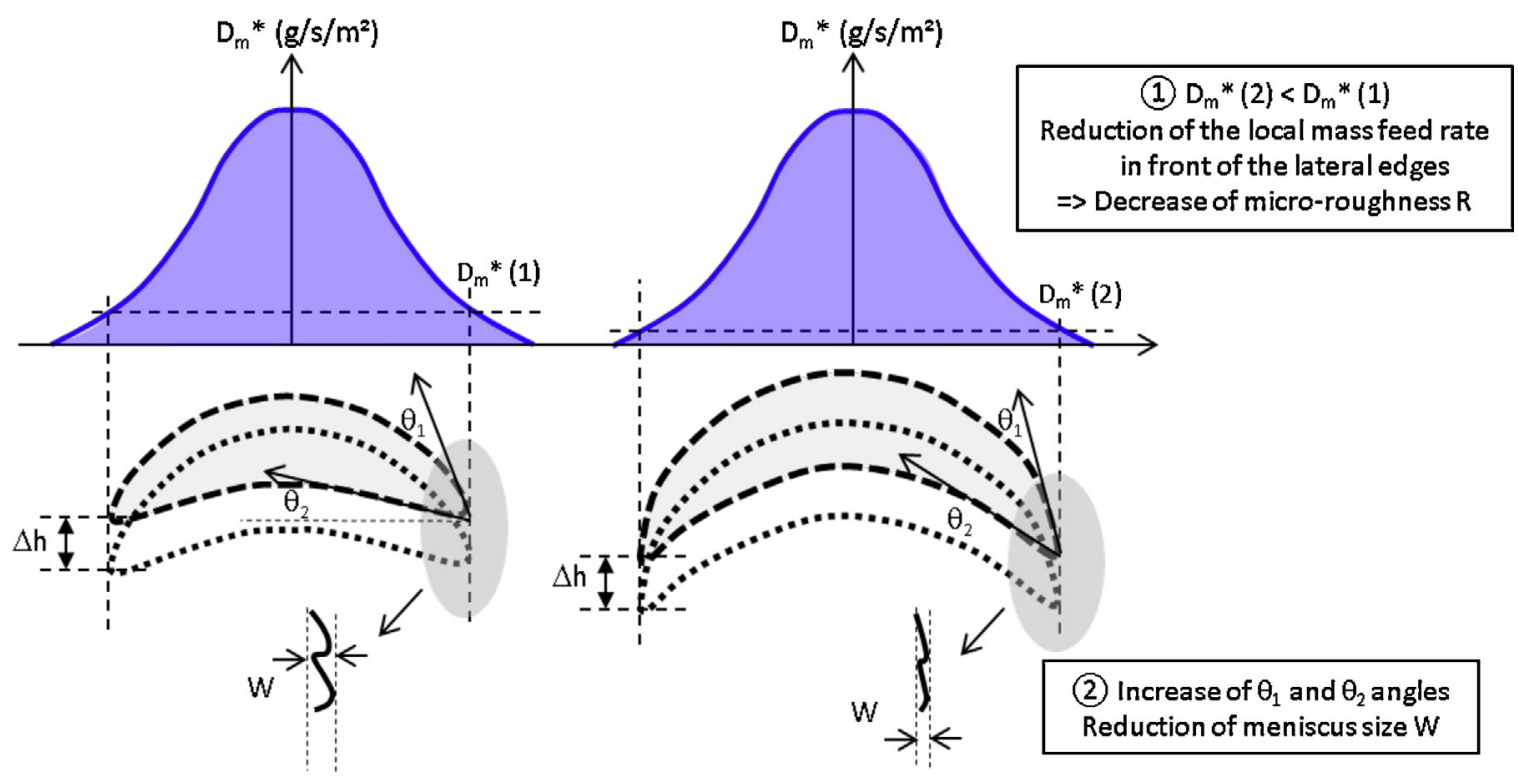

Fig. 16. Influence of $\theta_{1}$ and $\theta_{2}$ lateral melt pool angles on meniscus amplitude for similar $\Delta h$ values. An increase of $\theta_{1}$ and $\theta_{2}$ angles is beneficial for surface finish. 
Table 2

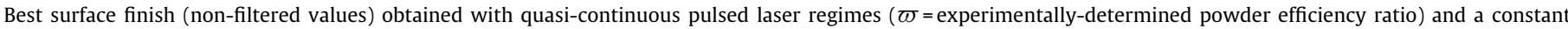
$D_{\mathrm{m}}=1 \mathrm{~g} / \mathrm{min}\left(R_{\mathrm{t}}=\right.$ total roughness amplitude = peak value - valley value $)$. Measurements have been carried out along the $-z$ direction.

\begin{tabular}{|c|c|c|c|c|}
\hline DMD conditions & $R_{\mathrm{a}}(\mu \mathrm{m})$ & $R_{\mathrm{p}}(\mu \mathrm{m})$ & $R_{\mathrm{t}}(\mu \mathrm{m})$ & $\varpi$ \\
\hline Gaussian $1.2 \mathrm{~mm}-P_{\text {peak }}=600 \mathrm{~W} 100 \mathrm{~Hz}(\tau=9 \mathrm{~ms}, \mathrm{dc}=0.9)$ & 2.5 & 6.6 & 13.4 & 0.51 \\
\hline Gaussian $1.2 \mathrm{~mm}-P_{\text {peak }}=500 \mathrm{~W} 100 \mathrm{~Hz}(\tau=9 \mathrm{~ms}, \mathrm{dc}=0.9)$ & 5.2 & 10.5 & 20 & 0.5 \\
\hline Top-Hat $1.7 \mathrm{~mm}-P_{\text {peak }}=800 \mathrm{~W} 100 \mathrm{~Hz}(\tau=9.3 \mathrm{~ms}, \mathrm{dc}=0.93)$ & 3 & 18.1 & 27.5 & 0.77 \\
\hline
\end{tabular}

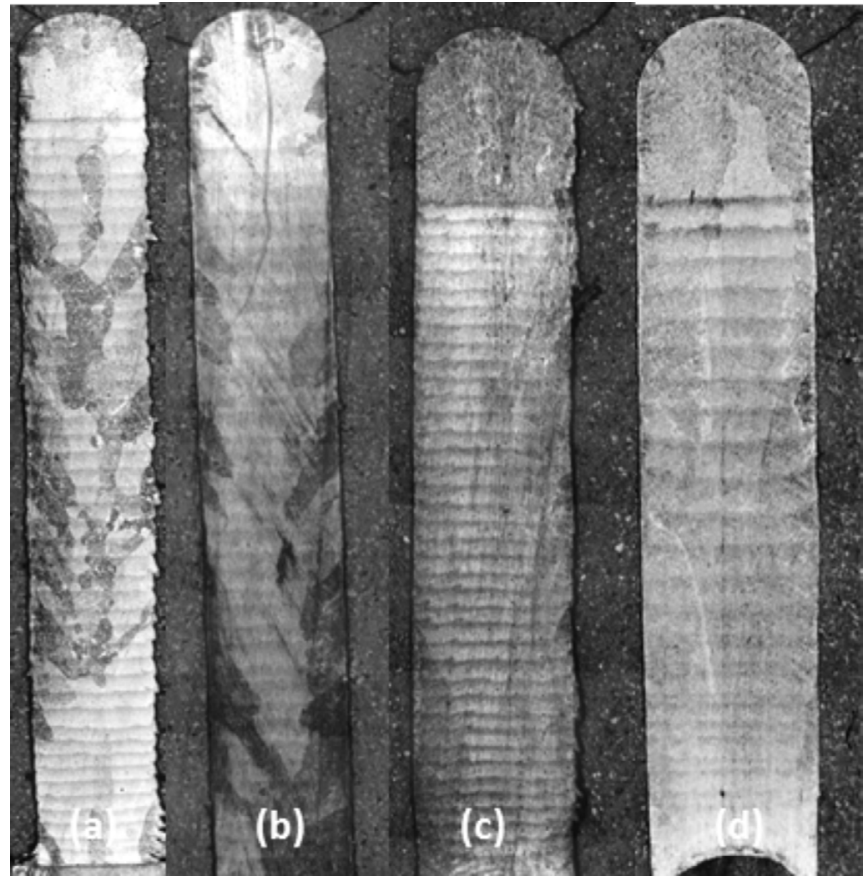

Fig. 17. Improvement of surface finish using an increase of duty cycles on DMD-manufactured walls $\left(P_{\text {peak }}=500 \mathrm{~W}, f=100 \mathrm{~Hz}, V=0.4 \mathrm{~m} / \mathrm{min}\right)$, (a) dc $=0.45$, (b) $\mathrm{dc}=0.6,(\mathrm{c}) \mathrm{dc}=0.75$, (d) dc $=0.9$.

manufactured in pulsed regime or in cw regime: all the samples were shown to exhibit $\mathrm{HV}_{0.1}=420 \pm 20$ whatever the process conditions. Consequently, and even if further experiments (electron microprobe analysis etc.) should be done to provide more precise data than EDS on the chemical content of DMD walls, it could be assumed that improved surface finish could be obtained together with satisfactory metallurgical behavior, even when carried out with rather high peak powers.

However, a more detailed metallurgical investigation of pulsed DMD structures will have to be carried out to investigate the specificity of a pulsed laser regime versus grain morphology, microstructures and resulting mechanical properties.

More widely, it should also be interesting to address in the near-future the influence of the thermo-physical properties of the projected material on the surface finish, which is still difficult to estimate as a whole.

\section{Conclusions}

The following conclusions can be drawn from this study:

- This work demonstrated experimentally that the use of quasicontinuous instead of fully continuous laser irradiations can represent a new way to improve the surface finish of Ti64 parts produced by DMD. This was attributed to reduced thermal gradients and Marangoni lateral flow in the melt pool.

- With such laser irradiations, combined with low mass feed rates $\left(D_{\mathrm{m}}=1 \mathrm{~g} / \mathrm{min}\right)$ resulting in thin additive layers $(\Delta h<0.2 \mathrm{~mm})$, average roughness values $R_{\mathrm{a}}$ of near $3 \mu \mathrm{m}$ and peak-to-average values $R_{\mathrm{p}}$ near $10 \mu \mathrm{m}$ could be obtained, which result appears to be a huge improvement, compared with previous data reported in the literature.

- The combination of a pulsed regime with a uniform "top-hat" irradiation was not shown to add further improvement to surface finish.

These results tend to indicate that using a pulsed laser operating mode, the DMD process can be envisaged for manufacturing near net-shape parts, with limited post-machining steps.

\section{Acknowledgments}

The authors acknowledge the financial support of French National Agency for Research (ANR) under the frame of the ASPECT Project (ANR-09-BLAN-0014). The SEM investigations have been performed on the FEG-HITACHI 4800 of PIMM which has been funded with the help of the SESAME program of Île-de-France Region, Arts et Métiers ParisTech and CNRS.

\section{References}

Alimardani, M., Fallah, V., Iravani-Tabrizipour, M., Khajepour, A., 2012. Surface finish in laser solid freeform fabrication of an AISI 303L stainless steel thin wall. Journal of Materials Processing Technology 212, 113-119.

Baufeld, B., Brandl, E., Van der Biest, O., 2011. Wire based additive layer manufacturing: comparison of microstructure and mechanical properties of Ti-6Al-4V components fabricated by laser-beam deposition and shaped metal deposition. Journal of Materials Processing Technology 211, 1146-1158.

Gharbi, M., Peyre, P., Gorny, C., Carin, M., Morville, S., Le Masson, P., Carron, D., Fabbro, R., 2013. Influence of various process conditions on surface finishes induced by the direct metal deposition laser technique on a Ti64 alloy. Journal of Materials Processing Technology 213, 791-800.

Kobryn, P.A., Semiatin, S.L., 2001. The laser additive manufacture of Ti-6Al-4V. Journal of Materials 53, 40-42.

Kumar, A., Roy, S., 2009. Effect of three-dimensional melt pool convection on process characteristics during laser cladding. Computational Materials Science 46, 495.

Maisonneuve, J., Colin, C., Aubry, P., 2007. Profil Project: direct manufacturing of aerospace components by laser cladding and laser sintering. In: Icaleo'2007 Conference, October, Scottsdale, USA.

Morville, S., 2012. PhD thesis, Modélisation thermohydraulique du procédé de fabrication Directe par Projection Laser en vue d'améliorer l'état de surface final. University of South Brittany, France.

Morville, S., Carin, M., Carron, D., Le Masson, P., Peyre, P., Gharbi, M., Gorny, C., Fabbro, R., 2011. 2D finite element modeling of heat transfer and fluid flow during multi layered DMD laser process. In: ICALEO'2011 International Conference, Orlando, USA, 17-21 October

Muller, M., Fabbro, R., El-Rabii, H., Hirano, K., 2012. Temperature measurement of laser heated metals in highly oxidizing environment using 2D single-band and spectral pyrometry. Journal of Laser Applications 24 (2), No. 022006.

Peyre, P., Neveu, R., Aubry, P., Fabbro, R., Longuet, A., 2008. Analytical and numerical modelling of the direct metal deposition laser process. Journal of Physics D: Applied Physics 41.

Pinkerton, A.J., 2010. Laser direct metal deposition: theory and applications in manufacturing and maintenance. In: Lawrence, J., Pou, J., Low, D.K., Toyserkani, E. (Eds.), Advances in Laser Materials Processing. Woodhead Publishing Limited, Ed CRC Press.

Pinkerton, A.J., Li, L., 2003. The effect of laser pulse width on multiple-layer 316L steel clad microstructure and surface finish. Applied Surface Science 208-209, 405-410.

Raphet, B., 2008. Etats de surface - Caractérisation. Techniques de l'Ingénieur R1230 (in French).

Xue, L., Li, Y., Wang, S., 2011. Direct manufacturing of net-shape functional components/test pieces for aerospace, automotive and other applications. Journal of Laser Applications 23 (4), 042004.

Zhu, G., Li, D., Zhang, A., Pi, G., Tang, Y., 2012. The influence of laser and powder defocusing characteristics on the surface quality in laser direct metal deposition. Optics \& Laser Technology 44, 349-356. 